\title{
3D modeling of underground objects with the use of SLAM technology on the example of historical mine in Ciechanowice (Ołowiane Range, The Sudetes)
}

\author{
Jaroslaw Wajs ${ }^{1, *}$, Damian Kasza ${ }^{1}$, Pawet P. Zagożdżon ${ }^{1}$, and Katarzyna D. Zagożdżon ${ }^{1}$ \\ ${ }^{1}$ Wrocław University of Science and Technology, Faculty of Geoengineering, Mining and Geology, \\ 27 Wyb. Wyspiańskiego St., 50-370 Wrocław, Poland
}

\begin{abstract}
Terrestrial Laser Scanning is a currently one of the most popular methods for producing representations of 3D objects. This paper presents the potential of applying the mobile laser scanning method to inventory underground objects. The examined location was a historic crystalline limestone mine situated in the vicinity of Ciechanowice village (Kaczawa Mts., SW Poland). The authors present a methodology for performing measurements and for processing the obtained results, whose accuracy is additionally verified.
\end{abstract}

\section{Introduction}

In the case of classic measurement methods applied for provide an inventory of underground objects, time required to perform survey work is relatively long. Such methods produce XYZ coordinates of specific points. Custom designed measurement networks can be applied for generate derivative products, such as horizontal and vertical cross sections, or volumetric measurements. Over the past two decades, rapid development of laser technologies has allowed producing high resolution 3D models.

The specific topology of such engineering objects as underground excavations frequently causes the measurements to require a significant amount of work $[1,2]$. Therefore, the dedicated measurement systems must be mobile and available for use in extreme conditions which exist in objects of this type [3]. For example, measurements of control points poses a real challenge in excavations of limited volume (limited vertical cross-section area).

This paper presents the results of research on applying SLAM (Simultaneous Localization And Mapping) technology in the acquisition of measurement and navigation data. The test object was a historic mine with a chamber in Ciechanowice (Ołowiane Mountains, the Sudetes range), in which crystalline limestone was mined [4, 5].

\footnotetext{
Corresponding author: jaroslaw.wajs@pwr.edu.pl
} 


\section{Characteristic of examined object}

The analyzed mine is located in the southern part of the Kaczawa Mountains, in the area of a small morphological unit called the Ołowiane (Lead) Mountains and - in administrative terms - in the peripheral, western part of Ciechanowice village (Fig. 1). The inlet of the adit is situated at a steep slope, about 50 meters above the Bóbr River (about $460 \mathrm{~m}$ a.s.1.). The mine was probably operating in the $19^{\text {th }}$ or $18^{\text {th }}$ century and the rock exploited (crystalline limestone) was used for firing lime in the lime kiln situated nearby (400 $\mathrm{m}$ to S).

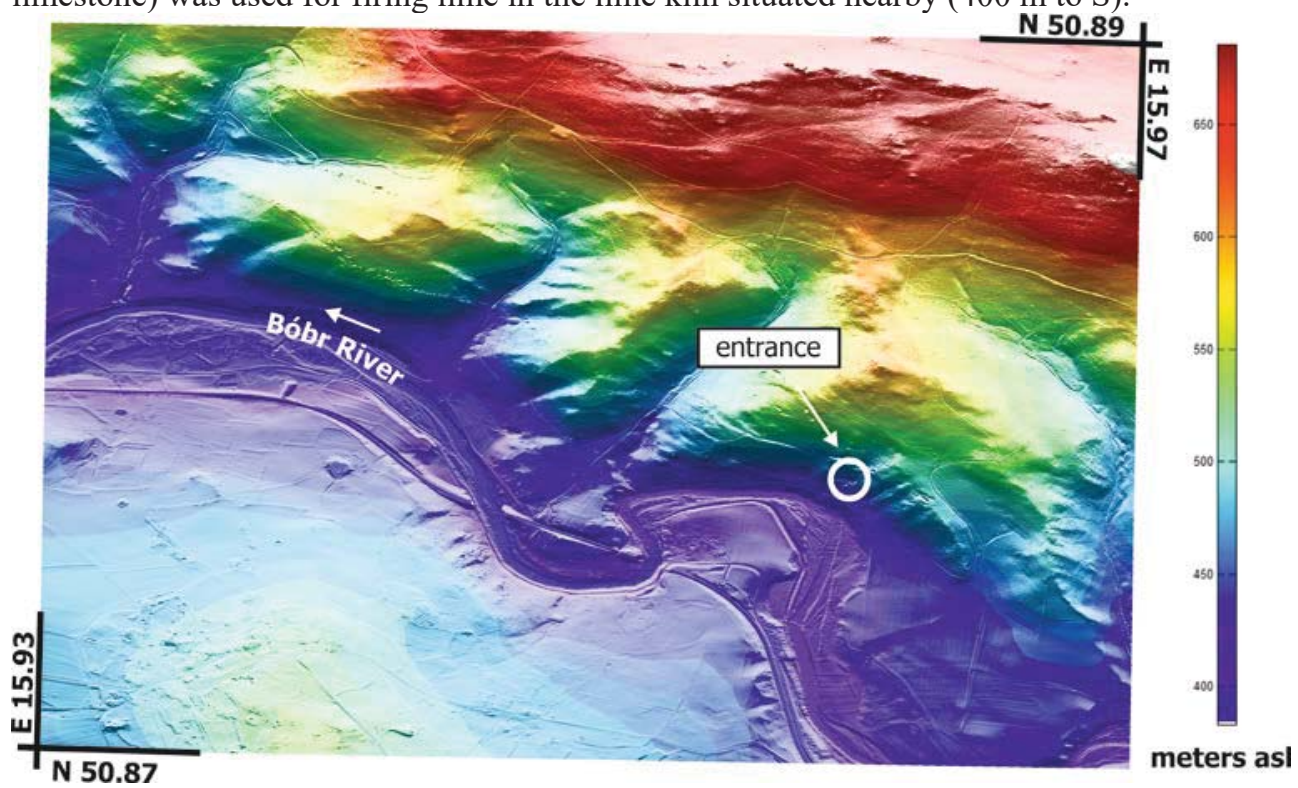

Fig. 1. Location of historic mine in Ciechanowice.

\subsection{State of preservation and geology}

The mine consists of an about 90 -meter long adit and a mining chamber. The adit runs straight towards NE. It is about $1.8 \mathrm{~m}$ wide and its height varies between $1.5 \mathrm{~m}$ and $2.3 \mathrm{~m}$.

The excavation is well preserved - small rocky screes are found only at the inlet and about $65 \mathrm{~m}$ from the entrance. A large exploitation chamber extends towards NW-SE (Fig. 2). Its length is about $30 \mathrm{~m}$, the width is up to $8 \mathrm{~m}$, and the height (in some places) exceeds $5 \mathrm{~m}$. The surface of the floor in the chamber is very irregular. Original level of the floor is preserved on the extension of the tunnel, but in the northern part of the chamber it is mostly covered with loose material (probably barren rock from other parts of the excavation), while the floor of southern part of chamber rises rapidly and large rock fragments separated from the roof cover to the floor. Behind the chamber, there is the final section of the adit, about $16 \mathrm{~m}$ in length.

The adit runs within rocks known as greenstones or greenstone schists [6-9]. These rocks are structurally diverse, and show partial folding. Fine lenses of pegmatite can be seen in several places. The chamber has been drivaged in crystalline limestone, although now (due to progressive falling off rock blocks from the roof) the walls of its southern part are also formed by greenstone. Two lithological varieties are distinguished among the limestones: light-colored massive and laminated. The contacts of all mentioned rocks are clearly visible [4]. 
In the excavations, a specific ecosystem has been evolved, inhabited by species of insecticidal fungi [10]. Additionally, the exploitation chamber comprises many clearly visible hand-drilled blastholes which remain after breaking rock with black powder. For these reasons, the mine is systematically researched as an object interesting from the viewpoint of geology, biology, and history of mining, and is being prepared for protection.

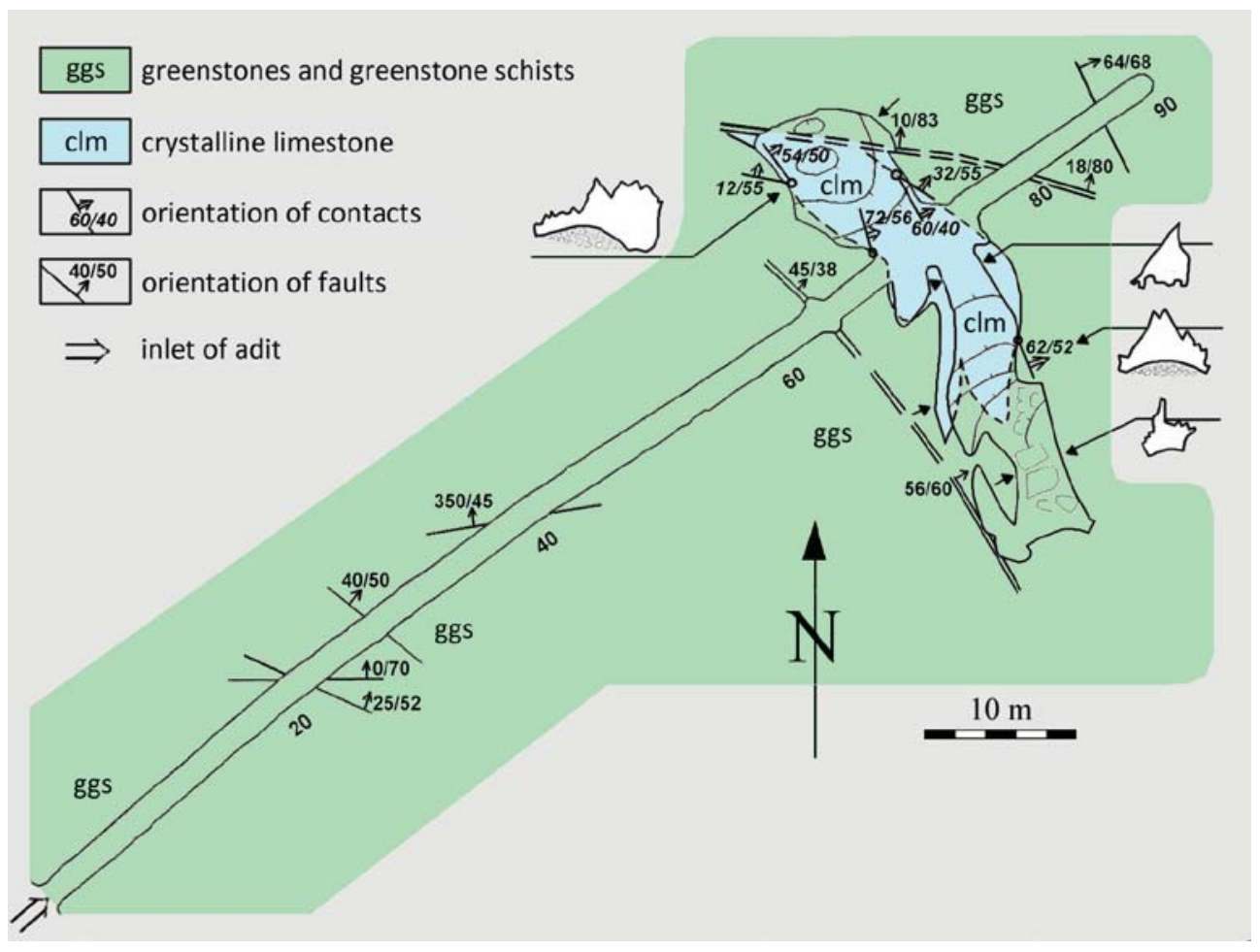

Fig. 2. Geological map of the historic mine in Ciechanowice.

\section{Survey work}

As is typically the case in single hole excavations, the geodetic control network in the Ciechanowice adit is an open polygon, which offers limited accuracy. A more advantageous solution consists in constructing a closed polygon, in which the first measurement point coincides with the last point, in this case the point being located at the entrance to the adit.

In many cases, performing measurements with the use of TLS (Terrestrial Laser Scanning) technology is very time consuming due to a large number of measuring stations [11]. This is because the extensive range of terrestrial lasers cannot be efficiently used in objects of this type. Errors, i.e. incomplete 3D models, frequently result from inappropriate choice of stations and the consequent discontinuity of the mesh surface. In order to minimize the influence of the above negative factors, the present research has been performed using SLAM technology.

\subsection{SLAM measurement technology}

Implementation of the SLAM technology in positioning allows collecting the measurement data in parallel with the navigation data [12]. Kalman filtering [13] allows integrating 
LiDAR (Light Detection and Ranging) observations with the IMU (Inertial Measurement Units) data. The analyzed object was scanned with the use of the GeoSLAM ZEB-REVO handheld revolving laser-scanner.

The scanner is equipped with a revolving $360^{\circ}$ camera capable of producing highresolution point clouds. Alongside with the LiDAR measurements, as the scanner passes through the survey environment, the sensor's 3D trajectory is recorded on the basis of the built-in IMU.

\subsection{Measurement sessions}

The analyzed object was measured in two sessions, which provided data for IQC (Internal Quality Control). The first measurement session lasted 15 minutes and covered the total AOI (Area of Interest). The subsequent quality control session was independent and lasted 35 minutes.

\section{Data processing}

The obtained raw measurement data were processed using dedicated GeoSLAM Desktop application. The generated metric products were based on a primary result, i.e. on the adjusted 3D trajectory along with its conditioning. The processed point clouds were recorded in the binary standard ISPRS.LAS 1.3.

An additional product generated by the GeoSLAM Desktop software are comprised pct_shaded point clouds as well as point clouds whose color corresponded to the distance value in relation to the trajectory in PLY format, representing every $11^{\text {th }}$ point from the original set. During the first measurement session, $29,606,712$ points were recorded $(0.8$ GB capacity). This measurement provided reference data for further analyses. The resulting data set comprised $78,469,866$ points $(2.15 \mathrm{~GB})$.

The resulting point cloud may be analyzed using various methods what was discussed by Samieinejad et al. [14]. The obtained 3D models may be conditioned by visual inspection of the model's continuity, volumetric analysis [15], or in a point-to-point approach, as is the case in this work.

The point-to-point methodology of point cloud processing has been described by Holst et al. [16]. At present, the most frequently used cloud point analysis algorithms include Cloud-to-Cloud (C2C) analysis, Multiscale-Model-to-Model-Cloud (M3C2) analysis, Cloud-to-Mesh (C2M) and Mesh-to-Mesh (M2M) analysis. The main criterion in the point cloud analyses was Internal Quality Control. The analyses were performed in the Cloud Compare application, using the $\mathrm{C} 2 \mathrm{C}$ function and the $\mathrm{M} 3 \mathrm{C} 2$ distance analysis [17].

The analyses were divided into a total test and a local test. The total test provided information on the integrity of the measurement range and on potential gross errors (Figs. 4,6 ), while the local test consisted in inspecting the point cloud after the outlier values have been discarded (Figs. 3, 5). 


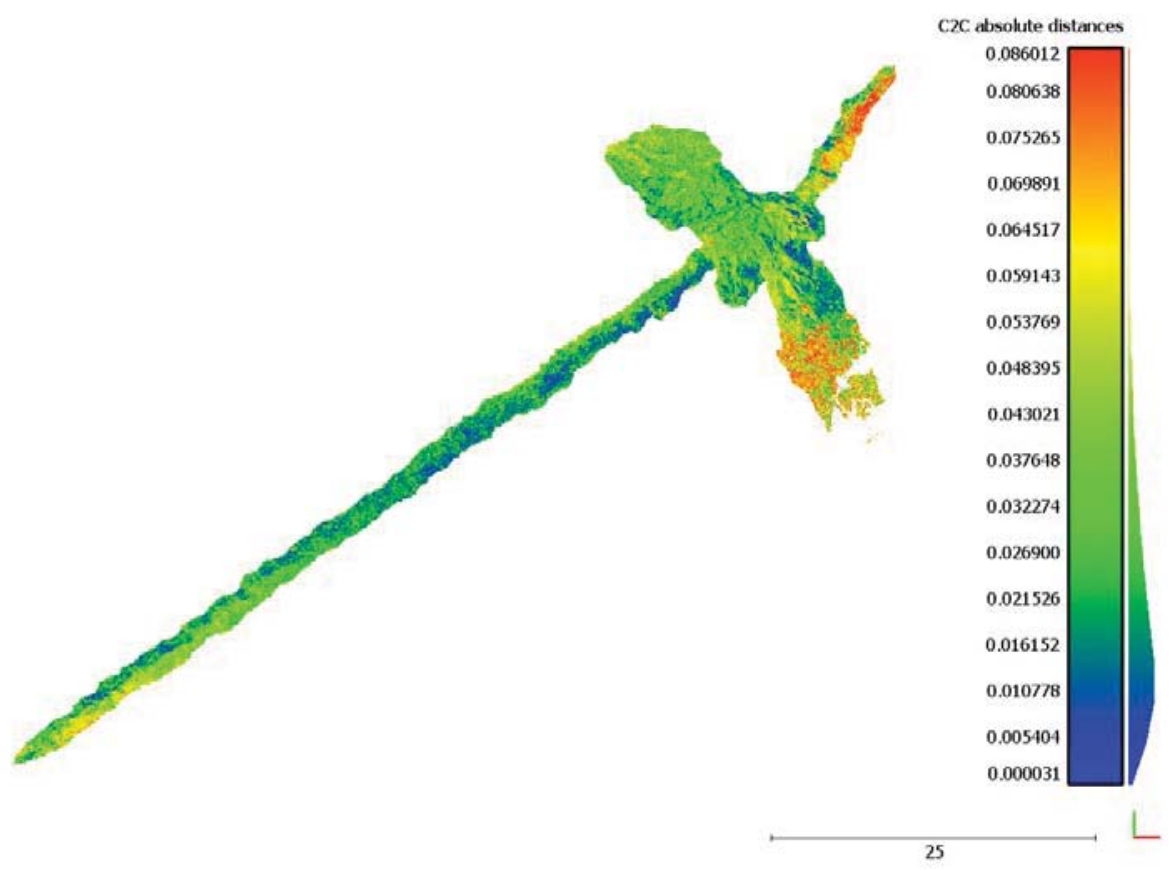

Fig. 3. Local test results analyzed using the $\mathrm{C} 2 \mathrm{C}$ distances algorithm.

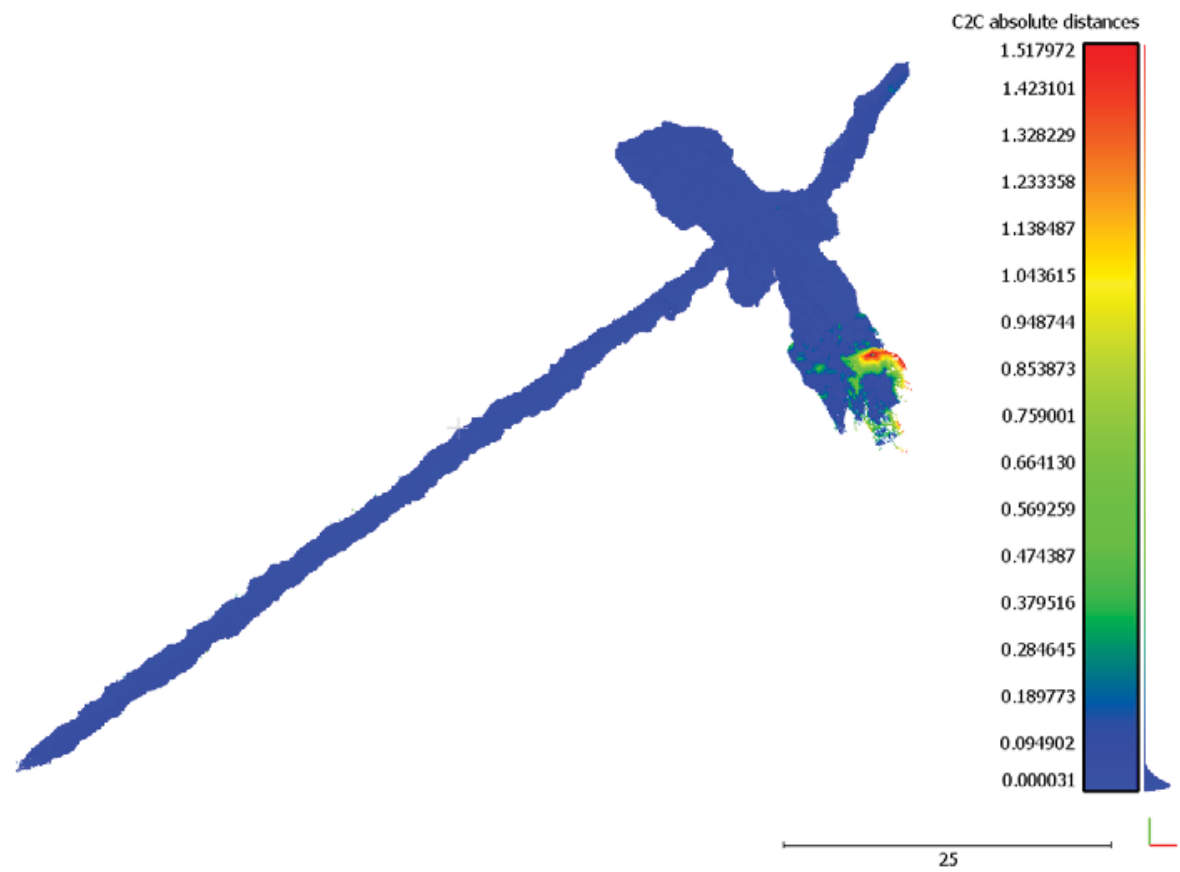

Fig. 4. Global test results analyzed using the $\mathrm{C} 2 \mathrm{C}$ distances algorithm. 


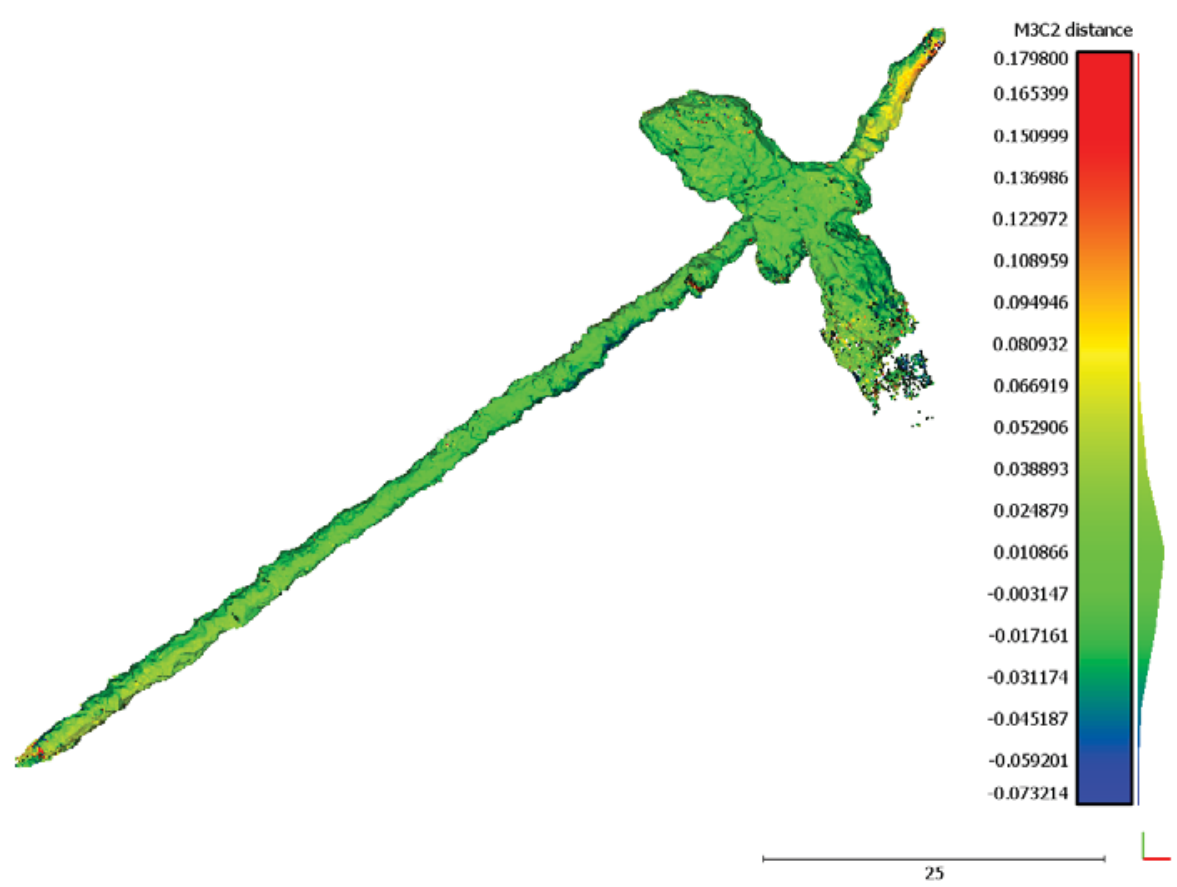

Fig. 5. Local test results analyzed using the $\mathrm{M} 3 \mathrm{C} 2$ distances algorithm.

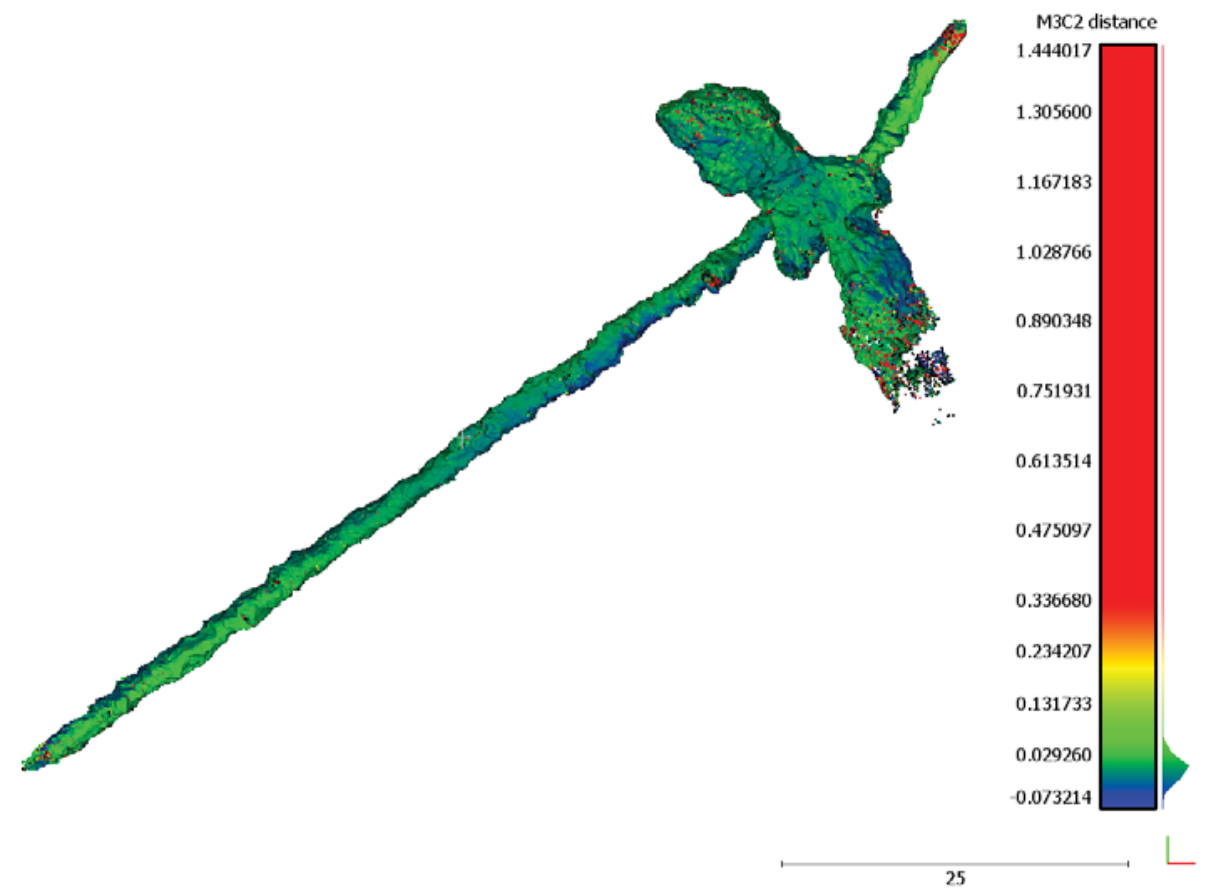

Fig. 6. Results of the global test analyzed using the $\mathrm{M} 3 \mathrm{C} 2$ distances algorithm 


\subsection{Construction of the 3D model}

Prior to developing a mesh model in the MeshLab application, the packet of the combined measurement data required further processin. The points located outside the excavation (fragments of the surface area and vegetation) were removed manually, as was the so-called noise, i.e. points located in the immediate vicinity of the scanned area, but not included in this area (location error of laser beam deflection point). In addition, a Poisson-disk sampling filter [18] was applied to the set in order to unify the point cloud (minimum distance between the adjacent points was set at $50 \mathrm{~mm}$ ). This operation reduced point density in the locations where scans overlap, and hence improved the balance of point distribution in the scanned area.

After the above operations have been carried out, the developed mesh models were tested for their accuracy depending on the four defined parameters of the Poisson surface reconstruction algorithm $[19,20]$. Octree depth - the most important of these parameters defined the recursion degree of the tree data structure, and consequently offered greater accuracy to the developed mesh model. For the defined density of the scanned surface points and for the value of this parameter being $>12$, no increase in the quality of the obtained models was observed. The remaining factors, which influence the use of the computing power, the minimum number of points visible in the tree branch and the isosurface compensation method were left at default levels $(8 ; 1 ; 1)$.

\section{Discussion}

The Internal Quality Control of the data collected from two independent measurements performed with the GeoSLAM ZEB-REVO scanner showed that the obtained sets of points have various density, which is directly related to the survey data acquisition time. Both for the $\mathrm{C} 2 \mathrm{C}$ and for the $\mathrm{M} 3 \mathrm{C} 2$ method, global tests showed that maximum distance values between the analyzed clouds were at an average of $0.02 \mathrm{~m}$ and at a maximum of $1 \mathrm{~m}$, thus enabling the identification of those locations which were not scanned twice. The $\mathrm{C} 2 \mathrm{C}$ analysis in the local test showed the compared point clouds to be consistent. The average value of shift between the clouds was $2 \mathrm{~cm}$. Maximum distance values for the analyzed clouds were $7.5 \mathrm{~cm}$. The local test based on the $\mathrm{M} 3 \mathrm{C} 2$ method indicated that the average distances between the analyzed data sets were at $1.5 \mathrm{~cm}$. Importantly, the results based on the $\mathrm{M} 3 \mathrm{C} 2$ method represent an actual value of distances between the clouds, with allowance for negative values. Histograms from the analyses based on the $\mathrm{C} 2 \mathrm{C}$ algorithm represent distance as an absolute value.

The mesh-type structure based on the point cloud was used to construct a local geological model. The metrical model of the excavation allowed the representation to be supplemented by prior measurements of the tectonic structures [4]. Due to the high resolution of the mesh surface, it was possible to identify and plot the fault zones and the contacts of petrographic variations (Fig. 7). 


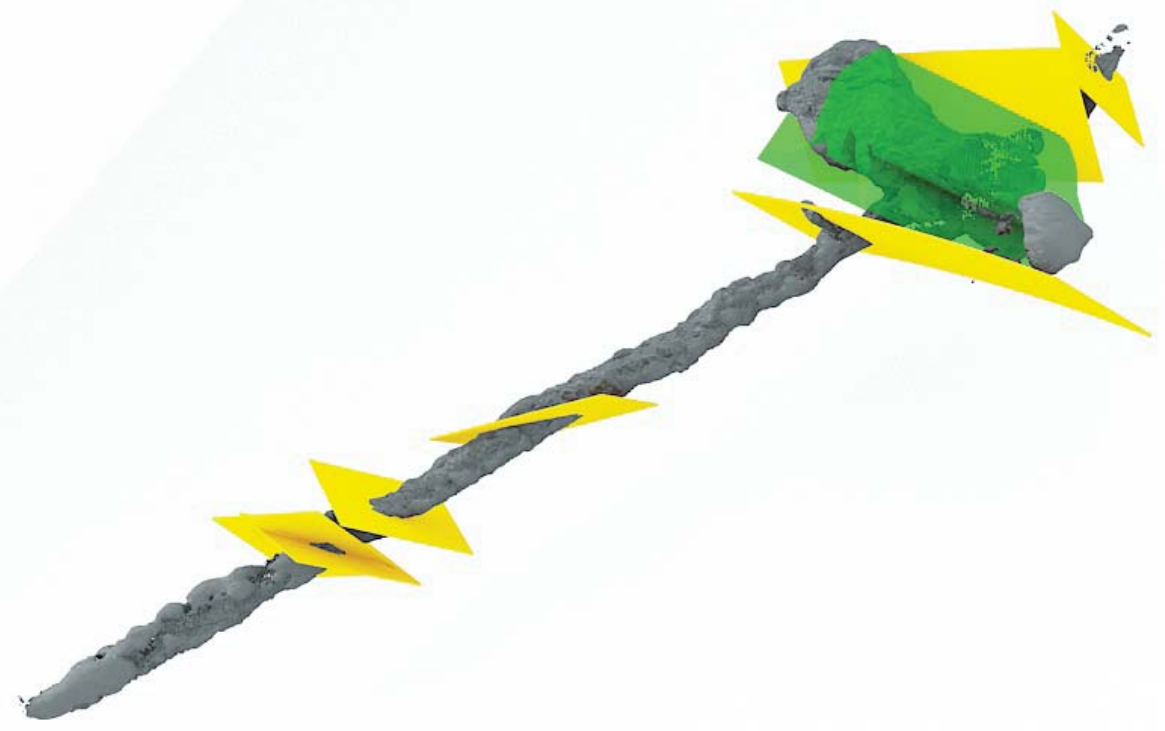

Fig. 7. 3D geological model of the surveyed area: adit (grey), faults (yellow) and body of crystalline limestone (green).

\section{Conclusions}

The results of the analyses show that the final product, i.e. the adjusted point cloud, represents a metric model of actual world-scale objects. If all the construction requirements are observed when using the SLAM technology to adjust the trajectory, it is possible to obtain a cloud of points unbiased with such errors as drift. Moreover, the analyses indicate that the two compared data sets comprise cohesive and repeatable data. The global test showed that the analyzed data also comprise areas with "insufficient data" - the so-called gaps, which result from different measurement rate and from different trajectories in the two measurement sessions. Internal quality control was positive. The obtained mean distance values between the analyzed point clouds were 4-5 cm, which is in accordance with the specification provided by the manufacturer. The results are shown in Fig. 8. On the Fig $8 \mathrm{a}$ the global integrity of the analyzed point cloud is $7 \mathrm{~cm}$. The local test at Fig $8 \mathrm{~b}$ shows that the mean biases is $2 \mathrm{~cm}$. At the Fig $8 \mathrm{c}$ and $8 \mathrm{~d}$ the presented M3C2 offset is about $5 \mathrm{~cm}$.

Terrestrial Laser Scanning is currently one of the fastest and most effective methods for acquiring information about an object's topography It allows fast and precise reconstruction of scanned objects in virtual reality, and in addition it enables them to be referenced against the already existing numerical information, such as LiDAR data.

The presented method of data processing and analysis proves useful in a number of cases. Primarily, it offers a significant aid in works related to geological surveying. The unique possibility to observe the rock mass from the inside (by penetrating excavations) and to perform the above described works allowed the construction of a digital, spatial geological model of the surveyed area. 
C2C absolute distances (7133625 values) [256 classes]

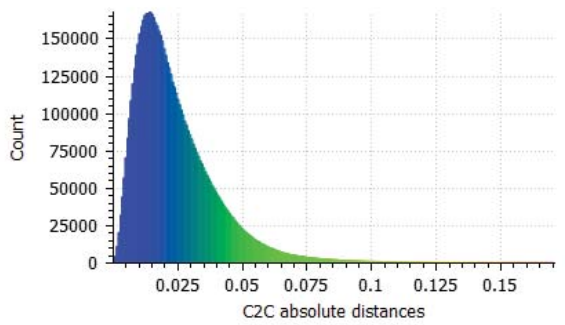

a

M3C2 distance (2691520 values) [256 classes]

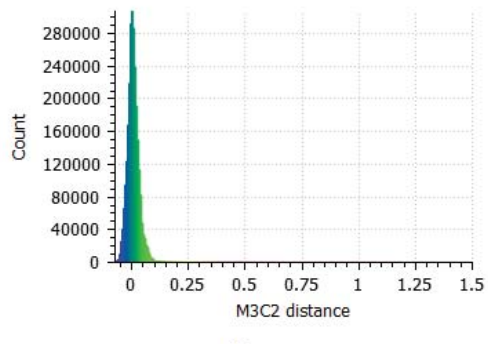

C
C2C absolute distances (7133625 values) [256 classes]

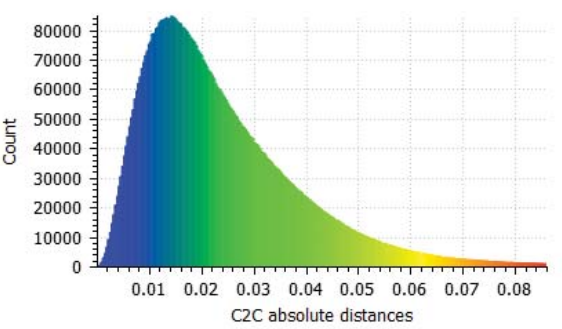

b

M3C2 distance (2691520 values) [256 classes]

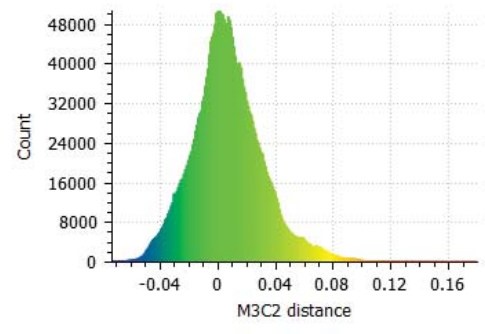

d

Fig. 8. Histograms of biases in (a) C2C global tests, (b) $\mathrm{C} 2 \mathrm{C}$ local tests, (c) $\mathrm{M} 3 \mathrm{C} 2$ global tests, and (d) $\mathrm{M} 3 \mathrm{C} 2$ local tests.

This work was financed by the Polish Statutory Research Grant no. 0402/0137/16, 0402/0146/16 and Grant no. 0401/0128/17.

\section{References}

1. R. Kershaw, Helictite 41, 87-94 (2012)

2. C. Baselgia, M. Bosse, R. Zlot, C. Holenstein, Field and Service Robotics, Results of the 8th International Conference, K. Yoshida and S. Tadokoro (eds.), Springer Tracts in Advanced Robotics 92, 541-554 (Berlin, 2014)

3. C. Holenstein, R. Zlot, M. Bosse, IEEE/RSJ International Conference on Intelligent Robots and Systems, 3830-3837 (San Francisco, CA, 2011)

4. P. Zagożdżon and K. Zagożdżon, Miesięcznik WUG 4 (152) (2007)

5. J. Wajs, D. Kasza, P. Zagożdżon, K. Zagożdżon, XVII ${ }^{\text {th }}$ Conference of PhD Students and Young Scientists, May 23-26, Szklarska Poręba, Poland (2017)

6. G. Berg, Geologische Karte von Preussen und benachbatren deutschen Ländern. Erläuterungen zu Blatt Kupferberg, II Aufl. Preuss. Geol. Landesanst (1938)

7. G. Berg, Geologische Karte von Preussen und benachbatren deutschen Ländern. Blatt Kupferberg, II Aufl. Preuss. Geol. Landesanst. (1940)

8. J. Szałamacha, Detailed geological map of the Sudetes 1:25000. Sheet Janowice Wielkie, Wyd. Geol. (1956)

9. J. Szałamacha, Explanations to detailed geological map of the Sudetes 1:25000. Sheet Janowice Wielkie, Wyd. Geol. (1969) 
10. W. Pusz, J. Grzeszczuk, P. P. Zagożdżon, W. Kita, Pol. J. Environ. Stud. (to be published)

11. M. Gallay, J. Kaňuk, Z. Hochmuth, J. D. Meneely, J. Hofierka, V. Sedlák, International Journal of Speleology, 44 (3), 277-291 (2015)

12. B. Mu, S. Y. Liu, L. Paull, J. Leonard, J. P. How, IEEE/RSJ International Conference on Intelligent Robots and Systems, $4602-4609$ (2016)

13. R.E. Kalman, J. Basic Eng 82(1), 35-45 (1960)

14. M. M. Samieinejad, N. Hosseini, K. Ahangari, Journal of Mining \& Environment, Vol. 8, No.3, 455-465 (2017)

15. J. Wajs, Mining Science, vol. 22, 75-83 (2015)

16. C. Holst, B. Schmitz, H. Kuhlmann, Terrestrisches Laserscanning 2016 (TLS 2016), C. Holst (Ed.), 39-58 (2016)

17. D. Lague, N. Brodu, J. Leroux, ISPRS Journal of Photogrammetry and Remote Sensing, 82, 10-26 (2013)

18. M. Corsini, P. Cignoni, R. Scopigno, IEEE Transaction on Visualization and Computer Graphics, Volume 18, Number 6, 914-924 (2012)

19. M. Kazhdan, M. Bolitho, H. Hoppe, Eurographics Symposium on Geometry Processing, Alla Sheffer and Konrad Polthier (eds.), The Eurographics Association, 61-70 (2006)

20. M. Bolitho, M. Kazhdan, R. Burns, H. Hoppe, Advances in Visual Computing, Lecture Notes in Computer Science, Springer, Volume 5875, 678-689 (2009) 